\title{
Modelling global material stocks and flows for residential and service sector buildings towards 2050
}

\author{
Sebastiaan Deetman a, c, *, Sylvia Marinova a , Ester van der Voet ${ }^{a}$, Detlef P. van Vuuren ${ }^{\text {b, c }}$, \\ Oreane Edelenbosch ${ }^{\mathrm{d}}$, Reinout Heijungs ${ }^{\mathrm{a}} \mathrm{e}$ \\ a Institute of Environmental Sciences, Leiden University, Leiden, the Netherlands \\ ${ }^{\mathrm{b}}$ PBL Netherlands Environmental Assessment Agency, The Hague, the Netherlands \\ ' Copernicus Institute for Sustainable Development, Utrecht University, Utrecht, the Netherlands \\ d Department of Management and Economics, Politecnico di Milan, Via Lambruschini 4/B, Milan, Italy \\ ${ }^{\mathrm{e}}$ Department of Econometrics and OR, Vrije Universiteit Amsterdam, Amsterdam, the Netherlands
}

\section{A R T I C L E I N F O}

\section{Article history:}

Received 30 January 2019

Received in revised form 19 September 2019

Accepted 29 September 2019

Available online 2 October 2019

Handling editor: Yutao Wang

\section{Keywords:}

Building materials

Floor space demand

Dynamic stock modelling

Circular economy

Scenario assessment

\begin{abstract}
A B S T R A C T
Residential buildings and service sector buildings have an important contribution to climate change, directly via energy use in these buildings and indirectly through construction activities and the production and disposal of buildings materials. In this paper, we introduce a model that looks at total global building stock for 26 regions between 1970 and 2050 and calculates the floor space and building materials both in new buildings and in demolished buildings. For residential buildings, we build upon the work of Marinova et al. (2019, this issue), who used a building material database to come up with scenarios for materials in the residential building stock. This paper adds two things. First, we introduce a new regression-based model for service building floor space, recognizing 4 different types of servicerelated buildings. Secondly, we use a dynamic stock model, based on lifetime distributions found in literature, to calculate the construction (inflow) and demolition (outflow) of building floor space for both residential and service-related purposes. We combine this with data from the building material database to come up with scenarios for the annual demand for construction materials worldwide as well as an estimation of the availability of waste materials after building demolition towards 2050 . The model can thus be used to assess the potential for closing the material cycles in the construction sector, while distinguishing urban and rural areas explicitly. The results show that demand for construction materials will continue to increase in most regions, even in developed countries. Global demand for steel and cement for the building sector is estimated to be $769 \mathrm{Mt} / \mathrm{yr}$ and $11.9 \mathrm{Gt} / \mathrm{yr}$ respectively, by the end of the modelling period. This represents a respective growth of $31 \%$ and $14 \%$ compared to today. Drivers behind this are an expected growth of global residential building stock of about $50 \%$, and a growth of about $150 \%$ in the building stock for services. Our model projects that by 2050 , only $55 \%$ of construction-related demand for copper, wood and steel could potentially be covered by recycled building materials. For other materials the availability of scrap may be higher, reaching up to $71 \%$ of new demand in the case of aluminium. This means that in most regions urban mining cannot cover the growing demand for construction materials.
\end{abstract}

() 2019 Published by Elsevier Ltd.

\section{Introduction}

The construction of buildings is the main driver for demand of bulk material such as steel (Pauliuk et al., 2013), cement (Cao et al.,

\footnotetext{
* Corresponding author. Institute of Environmental Sciences, Leiden University, Leiden, the Netherlands.

E-mail address: deetman@cml.leidenuniv.nl (S. Deetman).
}

2017) and aluminium (Liu et al., 2012). Assessing the development of the building stock over time can thus help to assess trends in demand of construction materials in the future. This is critical to understand impacts on material cycles and the possibility of urban mining (Krook and Baas, 2013) and the circular economy (Ghisellini et al., 2016). In addition, because the production of construction materials is energy intensive (van Ruijven et al., 2016; Gutowski et al., 2013) this will help to assess future energy demand and 
consequential carbon emissions (Pauliuk and Müller, 2014; Müller et al., 2013).

Existing literature on the future development of building stocks is often focused on the consequences for direct energy consumption (typically 20\% of total end-use energy) (Sartori et al., 2009). (Kavgic et al., 2010)' (Vásquez et al., 2016). Studies that, in contrast, describe the materials used in the building construction often focus on a single country or region such as China (Cao et al., 2018)' (Huang et al., 2013)' (Hu et al., 2010) or within the Europe for example (Wiedenhofer et al., 2015; Sandberg et al., 2014). Some studies only address the historic development of in-use stocks (McMillan et al., 2010)' (Krausmann et al., 2017)' (Tanikawa et al., 2015), while the basis for studies dealing with future stock predictions varies from fixed average growth rates (Wiedenhofer et al., 2015), historic stock (Fishman et al., 2016) to population based growth, intensity of use curves (Hatayama et al., 2010) or by explicit modelling of lifestyle changes by modelling per capita floor space development (Müller, 2006; Daioglou et al., 2012). Many of these different methodological approaches to modelling the stocks and flows of construction materials are summarized in a recent review by Augiseau et al. (Augiseau and Barles, 2017), who also identify other differences between studies such as the materials under investigation or the building categories covered (e.g. residential buildings, or a broader definition), again emphasizing that studies either have a regional or local focus, and at the global scale, often focus on one material only (Hatayama et al., 2010; Liu et al., 2012).

There is thus a need for a global description of the long-term development of materials in the building stock based on a more systematic coverage of regions and materials and a more explicit depiction of building categories, including non-residential buildings. However, the availability of literature on scenarios for nonresidential building demand is scarcer than literature on residential buildings. Some studies model regional developments (Teh et al., 2017; Bressand et al., 2007; Coffey et al., 2009), but global scenario studies which discern non-residential buildings often lack the detail to be used in scenarios for material demand (Deng et al., 2012). The inferior coverage of non-residential buildings also translates to the data availability of material content in nonresidential buildings. For example, the majority of data points in a recently published database for material intensity research is on residential buildings (Heeren and Fishman, 2019).

This paper documents a first attempt to achieve a more systematic coverage of material demand scenarios in buildings by building upon recent work by Marinova et al. (2019). They used the available model output from the IMAGE integrated assessment model (Stehfest et al., 2014) to develop a scenario for the stock of 6 building materials in 4 different residential building types, based on the physical demand for residential floor space (in square meters) towards 2050, which was originally described by Daioglou et al. (2012). While the original IMAGE model provided residential floorspace (stock) in both urban and rural areas, data on several regions was used to define the share of building types in these rural areas and urban areas. As such, four building types were distinguished, being detached houses, semi-detached houses, apartments and high-rise buildings. As the share of these building types in the total residential stock differs between urban and rural areas, the urbanization trend was used to drive the shift in the demand of residential building types. Where possible, the work by Marinova et al. then used material intensities (in $\mathrm{kg} / \mathrm{m}^{2}$ of net floor area) specific to the four different residential building types to come up with scenarios for building materials in the stock towards the year 2050.

In this paper we use the developed model and database as described by Marinova et al. and add two things: 1) we define a model to derive the corresponding inflow and outflow of both the building stock (in $\mathrm{m}^{2}$ ) and the construction materials in kgs. 2) We define a model describing the development of floor space demand in the service sector. These non-residential buildings comprise of three commercial building types and one category describing other (non-commercial) service-related applications. Similar to the approach for residential buildings we also calculate the corresponding material stocks and flows for service sector buildings. The resulting model has a global coverage, but also a high level of detail, looking at 26 regions (See supplementary data). The model captures the development of urban and rural housing demand and describes four residential building types and another four servicerelated building types. The model also provides both stock and flow scenarios for a total of six construction materials (being steel, concrete, aluminium, glass, wood and copper). All this ensures that the model accounts for relevant dynamics such as urbanization trends, income saturation effects and shifts in building types, while providing a global and comprehensive overview of the development of construction material demand. The connection with the IMAGE model allows us to couple the model to existing scenarios such as the Shared Socio-economic Pathways (SSPs) (van Vuuren et al., 2017a). The model generates relevant output in a format that could easily be coupled to integrated assessment models to also calculate the indirect consequences of changes in energy demand.

For generating scenarios, we use the SSP2 elaboration of the IMAGE model as described by van Vuuren et al. (van Vuuren et al., 2017b) towards the year 2050. This scenario describes the potential future development in terms of median assumptions for population growth towards 9.2 Billion people globally by 2050 and GDP growth (of a factor 3.4 between 2010 and 2050).

By modelling the global material stocks and flows in buildings based on their explicit service in terms of per capita floor space (in $\mathrm{m}^{2}$ per person) we hope to contribute to a better understanding of one of the main drivers of bulk material demand in the global sociometabolic system (Pauliuk and Hertwich, 2015). In the results section, we will focus on the potential for closing the cycles of various building materials by 2050 from a global perspective. We do however present this work as an initial attempt, and are aware of its limitations as addressed in the Discussion section. We have documented and disclosed the assumptions, the data input, the model code as well as the detailed outcomes as much as possible in the supplementary information (SI), so that others should be able to build and improve upon our work.

\section{Methodology}

In a companion paper, Marinova et al. (2019) described a method for modelling residential building stock and materials for 4 building categories. Here, we add two key features. First, we extend the model to also cover building materials in a selection of servicerelated buildings. Secondly, we added the explicit modelling of inflows and outflows of floor space as well as building materials by means of a dynamic stock model. We start by describing the model on buildings in the service sector in section 2.1 and continue with the description of Inflow and Outflow modelling of building materials. The entire model is implemented in Python, for which the model code is available through a link in the Supplementary Information.

\subsection{Service sector buildings modelling}

\subsubsection{Demand for service sector floor space}

In contrast to the residential floor space demand, the IMAGE integrated assessment model does not provide any data on servicerelated or other non-residential floor space. Therefore we 
developed our own demand projections for the floor space in service-related buildings using regression analysis on data from the commercially available Navigant Global Building Stock Database (Machinchick and Freas, 2018). This Global Building Stock Database provides information on service floor space use at a country level basis for a time period from 2017 to 2026 , for 231 countries, and for eight different building types related to services, which we grouped to four service building types for use in our model, being:

1) offices

2) retail, shops and warehouses

3) hotels \& restaurants, and

4) other (a.o. educational buildings, hospitals, governmental buildings, but also buildings for assembly and public transportation)

Unfortunately, the building types used do not cover all nonresidential buildings as no data was available for industrial or agricultural floor space. Moreover, due the extremely heterogeneous nature, modelling of industrial and agricultural buildings is very hard. Altogether, these buildings are excluded from our analysis.

A regression analysis was performed to estimate a relationship between the per capita service sector floor space demand and the Service Value Added (SVA) per capita at a global level. We used the data for the year 2017 to perform our regression, because this was the only year representing historical data. In doing so we derive a relationship between sectoral income (SVA in US\$) per capita and service building stock (in terms of $\mathrm{m}^{2}$ ) per capita. Next, we assume this relationship to be time-independent and use it to project the future development of service related floor space demand towards 2050 , given the development of the population size and SVA in 26 regions according to the IMAGE model and the SSP scenarios. The data on the Gross Domestic Product (GDP, in US dollars at Purchasing Power Parity, PPP) per capita and the shares of the SVA were obtained for the year 2016 (the latest available year) from the United Nations statistics (UNData, 2018a; UNData, 2018b). After the omission of outliers like small-island states (e.g. Tuvalu) and citystates (e.g. Singapore) and countries for which no SVA was available from the UN statistics, the regression was performed on 147 remaining data points corresponding to individual countries that together represent $97 \%$ of the total global population and $96 \%$ of the global GDP. In the Supplementary Information we show the resulting regression fit to the data points.

Though we tested for the usefulness of several other models, we decided to use a Gompertz-type relationship, based on the superior $\mathrm{R}^{2}$ values and because the use of a Gompertz curve is similar to the approach taken for residential buildings (Daioglou et al., 2012). The Gompertz curve used is defined by the following equation:

$y=\alpha \cdot e^{-\beta \cdot e^{-\gamma x}}$

Here $y$ is the floor space demand for service sector buildings in square meter per capita, and $x$ is the Service Value Added per capita in 2016-US\$ per year for a particular country, in PPP. The coefficients $\alpha, \beta$ and $\gamma$ are the three Gompertz parameters, which were estimated using a least squares optimization routine from the scipy package implemented in a python script (See SI). Because the $\alpha$ parameter describes the maximum value of the curve, it represents the value at which the per capita service-related floor space demand reaches saturation. We use a boundary condition for the regression by defining an upper limit for $\alpha$, of $25.6 \mathrm{~m}^{2}$ per capita. This value is the maximum value found in the current data. We chose to employ this boundary condition on $\alpha$, because there is no historic evidence that its value could be higher. However, in the sensitivity analysis we explore the effect of choosing a higher value for $\alpha$.

Initial regression based on an unweighted least squares optimization method yielded proper fits $\left(\mathrm{R}^{2}=0.86\right)$, but unsatisfactory model validation for the year 2017 (the resulting model was underestimating the total global stock according to the original data for 2017, because most countries with a large population size were situated above the fitted curve). Therefore, it was decided to model the total service floor space demand using a weighted (or generalized) least squares model, where the uncertainty $\sigma$ was defined to be inversely proportional to the population size of a country. So a high population size would translate into a high certainty, thus a high importance in the regression, where we minimized the goodness-of-fit parameter, or the $\chi^{2}$, according to Bevington \& Robinson (Bevington and Robinson, 2003):

$\chi^{2}=\sum_{i=1}^{147}\left\{\frac{1}{\sigma_{i}^{2}}\left[y_{i}-y\left(x_{i}\right)\right]^{2}\right\}$

Though this method yields a lower $\mathrm{R}^{2}$ (=0.69; with weighting), it makes sure that the model is able to re-create the known global stock in 2017 more accurately compared to an unweighted regression model. The resulting parametrization for the Gompertz curve for the total service sector can be found in Table 1. For details on the exact definition of $\sigma$, please see the SI.

The modelled total service floor space resulting from the weighted regression was subsequently subdivided into floor space for the four service building types based on the relative contribution of these sectors at a given income level, based on their individually fitted curves (using weighting based on GDP per capita as a proxy for data reliability, see Supplementary Information). Thus, leading to a total of five regression models. The parameter setting resulting from these five regression curves (one population weighted, four weighted by GDP per capita) can be found in Table 1 , and the resulting relation between Service Value Added levels and service-related floor space demand can be seen in Fig. 1.

For the year 2017 the model leads to a global floor space demand of about 38 billion $\mathrm{m}^{2}$, of which $8 \%$ in hotels and restaurants, $13 \%$ from offices, $17 \%$ in retail \& warehouses and the remainder in other service-related buildings.

It is important to note that the current service floor space resulting from the model is slightly lower (by about 9\%) than the total stock in 2017 according to the Navigant Global Building Stock Database. A key reason for this is the difference in the country data used for deriving the model and the aggregated regional data in IMAGE (based on the SSP database and fractions for service valueadded from the World Bank). Secondly, the regression is based only on a selection of countries, so a perfect historical calibration remains impossible. Finally, and perhaps most importantly, the model assumes that floor space per capita depends on SVA per capita only, ignoring other factors. Examples of such factors are cultural habits, climatic conditions and population density. Even though the resulting model is slightly underestimating the current stock, we feel that given an acceptable $\mathrm{R}^{2}$ this global approach does allow for a useful estimation of the development towards the future, which is the main goal for this modelling exercise. We explore some options for alternative formulations of the regression model in the sensitivity analysis and we provide some reflections on future improvements regarding this issue in the Discussion section.

\subsubsection{Materials in service sector buildings}

The assumptions on the material demand for service sector buildings are simpler than those for the residential stock analysis 
Table 1



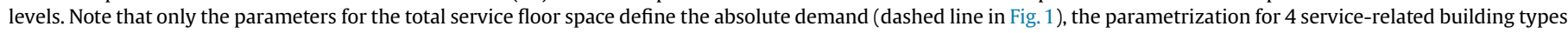
is only used to define the relative contributions.

\begin{tabular}{|c|c|c|c|c|c|}
\hline & $\alpha$ & $\beta$ & $\gamma$ & $\mathrm{R}^{2}$ & Weighting \\
\hline Offices & 4.253 & 5.54 & $6.95^{*} 10^{-5}$ & 0.80 & GDP/cap \\
\hline Retail, Shops \& Warehouses & 8.010 & 6.524 & $6.33^{*} 10^{-5}$ & 0.76 & GDP/cap \\
\hline Hotels \& Restaurants & 3.083 & 4.527 & $4.79 * 10^{-5}$ & 0.69 & GDP/cap \\
\hline Other & 9.980 & 2.652 & $5.17^{*} 10^{-5}$ & 0.77 & $\mathrm{GDP} /$ cap \\
\hline Services (total) & 25.601 & 3.289 & $7.22 * 10^{-5}$ & 0.69 & Population weighted \\
\hline
\end{tabular}

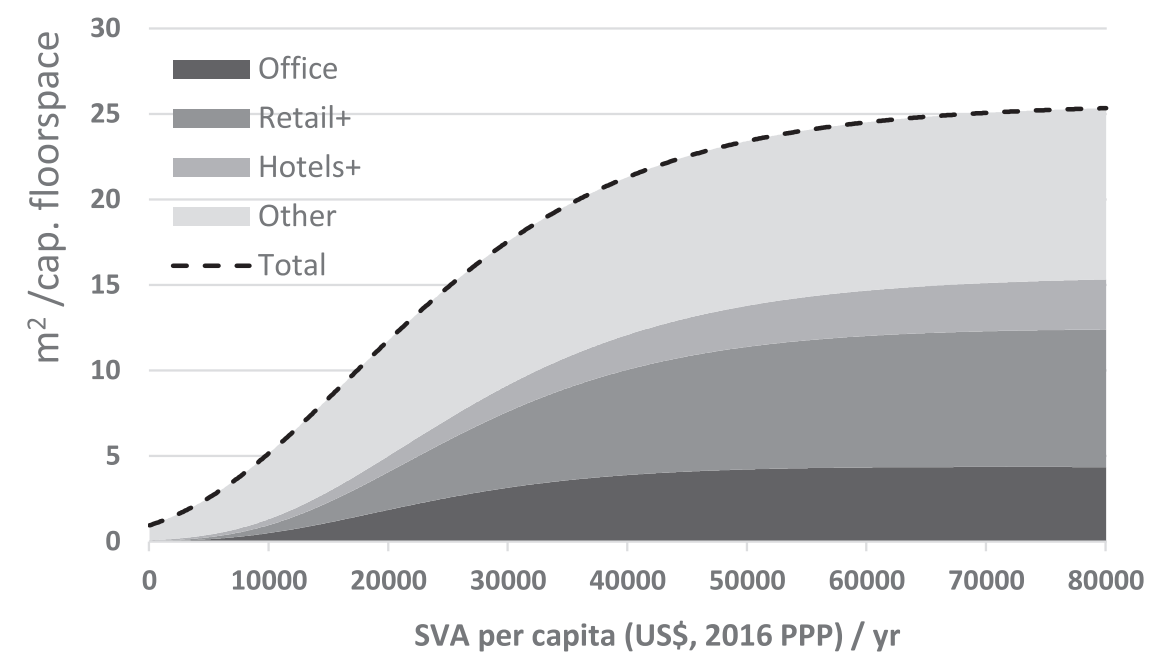

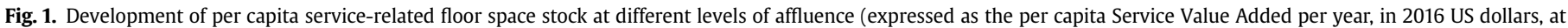
Purchasing Power Parity), as derived using a regression analysis as described (for more details, please see SI).

by Marinova et al. (2019). Because of a lack of data, the materials in service sector buildings are not defined regionally. Instead, a global average is used for the four service-related building types, in terms of kilograms per $\mathrm{m}^{2}$ of net floor space (i.e. the material intensity). Similar to our approach for residential building stock scenarios, we assume a static material intensity. The recently published database on building material intensities by Heeren et al. (Heeren and Fishman, 2019) provided a helpful starting point, but was supplemented with studies describing material intensities specific to the four service sector building types. It can be seen from Table 2 that the material content of retail \& warehouse buildings is based on four sources (Reyna and Chester, 2015; Schebek et al., 2017; Kellenberger et al., 2007; Gruhler and Deilmannl, 2017), while the offices were modelled based the average numbers found in six office specific studies (Reyna and Chester, 2015; Schebek et al., 2017; Kellenberger et al., 2007; Kashkooli et al., 2014; Kofoworola and Gheewala, 2009; Oka et al., 1993). For Hotels \& Restaurants we found three studies describing the building materials required for a hotel (Reyna and Chester, 2015; Gruhler and Deilmannl, 2017; Rosselló-Batle et al., 2010). Finally, material use in other service sector buildings was based on four studies describing materials in educational and other institutional buildings (Reyna and Chester, 2015; Gruhler and Deilmannl, 2017; Kumanayake et al., 2018; Marcellus-Zamora et al., 2016).

The inferred relation between income-levels and service floor space demand (stock, in $\mathrm{m}^{2} / \mathrm{cap}$ ), together with the static set of

Table 2

Material content assumptions $(\mathrm{kg} / \mathrm{m} 2)$ for the different service sector building types. See SI for details.

\begin{tabular}{|c|c|c|c|c|}
\hline & Offices & Retail \& Warehouses & Hotels \& restaurants & Other \\
\hline Based on & $\begin{array}{l}\text { Average of offices \& multi-storey } \\
\text { buildings in (Reyna and Chester, 2015; } \\
\text { Schebek et al., 2017; Kellenberger et al., } \\
\text { 2007; Kashkooli et al., 2014; Kofoworola } \\
\text { and Gheewala, 2009; Oka et al., 1993). }\end{array}$ & $\begin{array}{l}\text { Average of multiple shop types described } \\
\text { in (Reyna and Chester, 2015; Schebek } \\
\text { et al., 2017; Gruhler and Deilmannl, } \\
\text { 2017) and a hall-type building in } \\
\text { (Kellenberger et al., 2007) }\end{array}$ & $\begin{array}{l}\text { Average of a description of } \\
\text { multiple hotels in (Reyna and } \\
\text { Chester, 2015; Gruhler and } \\
\text { Deilmannl, 2017; Rosselló- } \\
\text { Batle et al., 2010) }\end{array}$ & $\begin{array}{l}\text { Average of various educational \& health } \\
\text { care buildings in (Reyna and Chester, } \\
\text { 2015; Gruhler and Deilmannl, 2017; } \\
\text { Kumanayake et al., 2018; Marcellus- } \\
\text { Zamora et al., 2016) }\end{array}$ \\
\hline Represents & Offices & Shops, Retail \& Warehouses & Hotels, Restaurants & $\begin{array}{l}\text { Hospitals, Educational, Institutional, } \\
\text { Transport, } \\
\text { Public assembly \& Others }\end{array}$ \\
\hline Steel & 115 & 78.5 & 84.4 & 101.9 \\
\hline Concrete & 905.1 & 700.1 & 724.2 & 1029.1 \\
\hline Aluminium & 4.8 & 2.4 & 4.4 & 5.8 \\
\hline Copper & 3.9 & 2.3 & 3.5 & 3.4 \\
\hline Wood & 6.7 & 11.2 & 18.5 & 25.5 \\
\hline Glass & 6.5 & 5.9 & 3.9 & 14.5 \\
\hline
\end{tabular}


building materials comprises the model for the service sector building material scenarios. Effectively the weight of materials in the service sector building stock for any IMAGE region at any time is given by the income level (US\$/cap), which through the Gompertz curve, gives an average floor space demand ( $\mathrm{m}^{2} /$ capita). This is multiplied by the population to get the total stock (in $\mathrm{m}^{2}$ ), which is then multiplied by the material content $\left(\mathrm{kg} / \mathrm{m}^{2}\right)$ to derive the development of construction materials in the building stock.

\subsection{Inflow and outflow of building materials}

\subsubsection{Dynamic stock modelling: life-times}

The combination of residential and service-related building stock as presented here, allows us to subsequently estimate building construction and building demolition activities (i.e. inflow $\&$ outflow of the building stock). This increases the relevance of the model output for policy questions related to the circular economy, in particular to assess whether construction materials could potentially be sourced from scrapped building materials. We applied a cohort-based dynamic stock model as developed by Pauliuk (Pauliuk and Heeren, 2018) with Weibull lifetime distributions to translate the scenarios on building stock into scenarios on the global inflow and outflow of building materials.

In order to simplify our initial model setup, we only account for the materials contained in the 'one-off' construction. So we do not take material losses into account, nor materials used for maintenance or building retrofits. Though this coverage would definitely be of interest, it remains outside the scope of this paper, as it would require elaborate and dedicated efforts given the global scope of our model.

Similar to the building stock, the inflow \& outflow of floor space is calculated on a square meter basis. We applied a cohort-based dynamic stock model, using a stock-driven approach, which implies that the stock prescribes the inflow as the sum of the stock addition plus the replacement of existing stock. Throughout the scenario period however, it happens occasionally in some regions that the drivers behind the stock are causing the building stock to shrink. Either due to a decline in population (e.g. for the former Soviet Union regions), or as a result of a decline in GDP (e.g. during the global economic crisis of 2008). In these cases, the stock driven model is required to balance the equation by immediately generating a large outflow. In realistic terms, this means that we do not account for vacant buildings. Even though we know that the share of vacant buildings can be significant. Typical values would be a $5 \%$ natural vacancy in urban areas (Zhang et al., 2018), but depending on market conditions, speculation could increase vacancy rates, like in China where vacancy rates are estimated to be over $20 \%$ of urban stock (Dericks et al., 2018).

For the building lifetimes we used values found in a literature review, which yielded 16 usable studies, which mostly identified a Weibull lifetime distribution. In correspondence with the resulting data, we chose to stick with this form of probability density function, but other options for modelling building lifetimes exist (Miatto et al., 2017), which were tested in the sensitivity analysis. Where possible we applied Weibull lifetime distributions specific to the building type and even the area. If this information was not available, we used one set of region specific Weibull parameters. If that was not available we used a global average lifetime distribution. However, for some regions we couldn't find lifetime distribution data, but we could find the mean lifetime. In these cases we used the global average shape parameter, but adjusted the scale parameter to correspond to the mean lifetime for that region. If no lifetime data for houses was available, we used a global average, corresponding to a mean lifetime of 60 years. For details of averaging distribution parameters, we refer to the Supplementary
Information. Table 3 shows a summary of the final set of applied Weibull parameters of residential buildings, which defines the fraction of buildings demolished for any given year after construction (for details see SI). For the lifetime of service-related buildings we applied one global distribution according to the Weibull shape parameter of 1.44 and a scale parameter of 49.6 , resulting in an average lifetime of $45 \mathrm{yr}$ according to combined data from (Kapur et al., 2008a; Daigo et al., 2007; Nomura and Suga, 2013). This is considerably lower than the lifetime of residential buildings in most regions, which has an effect on the material demand for service sector buildings as will be discussed in the following section.

Additional assumptions had to be made on how the building stock developed before the starting point of the scenario period, which is the year 1971 in our case. Since we do not have data on the age-distributions (i.e. the share of the stock by age-cohort) of buildings in that year, we needed to extend the historic time series to derive the age-distribution of buildings based on historic inflow as described in the SI.

\section{Results}

Here, we present results for residential and service-related building stock (Section 3.1), the resulting inflow and outflow of floorspace (Section 3.2) and the implications for material demand and recycling potential (Section 3.3).

\subsection{Comparing residential buildings \& service sector buildings}

Fig. 2 shows the resulting development of service sector building stock in the total number of square meters as compared to the (urban and rural) residential building stock, in eight regions, based on an average of recent history (2000-2015) and for the end of the scenario period (2035-2050). The service-related building stock will remain a small fraction of the entire building stock going up from about $16 \%$ now to a little over $23 \%$ of the total modelled stock globally, towards 2050. But it also shows that for some regions like Europe and North-America the service sector building stock substantially outweighs the rural residential building stock by the end of the scenario period, making it a relevant component of the building stock in absolute terms. Another reason why servicerelated building stock should not be overlooked is its growth rate. In fact, our model projects the growth of service-related building stock to be higher than the growth of residential building stock from a global perspective (between 2015 and 2050). This is in line with observations from literature (Deng et al., 2012) and examples from regular building surveys in the United States (IEA. Residential, 2015; IEA. Commercial, 2012).

Further detail on the share of service-related building types is shown in Fig. 3. It shows that global stock of service sector building types will grow by about $150 \%$ towards 2050 . Our model projections thus indicate that the building stock of services might expand more than twice as fast as the global residential building stock, which grows by roughly $50 \%$ over the same period. A closer look at the numbers behind Fig. 3 shows that the floor space demand for offices and retail grows a bit faster than for the other service sector building types, as a consequence of the regression analysis (see Table S4 in the SI).

\subsection{Results for building stock inflow and outflow}

Fig. 4 presents the results for the inflow and outflow of stock as derived using the dynamic stock model (the Figure shows 5-year moving average to smooth annual fluctuations). Interestingly, it is possible to distinguish three regional typologies. The first group 
Table 3

Summary of Weibull lifetime distribution parameters for residential buildings used in the dynamic stock modelling, and the resulting mean lifetimes.

\begin{tabular}{|c|c|c|c|c|}
\hline Region & shape & scale & mean lt (yr) & Sources \\
\hline Japan & 2.06 & 38.70 & 34 & (Daigo et al., 2017; Nomura and Suga, 2013) \\
\hline China & 2.00 & 44.43 & 39 & Wang et al. (2015a) \\
\hline Eastern Europe & 2.50 & 87.35 & 78 & Novikova et al. (2018) \\
\hline United States & 4.16 & 85.19 & 77 & (Olson, 2011; Kapur et al., 2008b; Hatayama et al., 2009) \\
\hline Western Europe & 2.95 & 70.82 & 63 & (Hatayama et al., 2009; Heeren et al., 2015; Davis et al., 2007) \\
\hline Canada & 1.97 & 57.53 & 51 & (Buyle et al., 2013a; Murakami et al., 2010a) \\
\hline Mexico & 1.97 & 63.17 & 56 & (Murakami et al., 2010b; OECD \& Eurostat, 2015) \\
\hline Brazil & 1.97 & 112.80 & 100 & Condeixa et al. (2017a) \\
\hline Rest of South America & 1.97 & 68.24 & 60.5 & (Murakami et al., 2010b; Olaya et al., 2017; Buyle et al., 2013b; OECD \& Eurostat, 2015) \\
\hline Southeastern Asia & 1.97 & 56.40 & 50 & Buyle et al. (2013b) \\
\hline Oceania & 1.97 & 94.00 & 83 & (Buyle et al., 2013b; Stephan and Athanassiadis, 2017). \\
\hline Global Average & 1.97 & 67.34 & 60 & average of parameters from Japan, China, US \& Europe \\
\hline
\end{tabular}

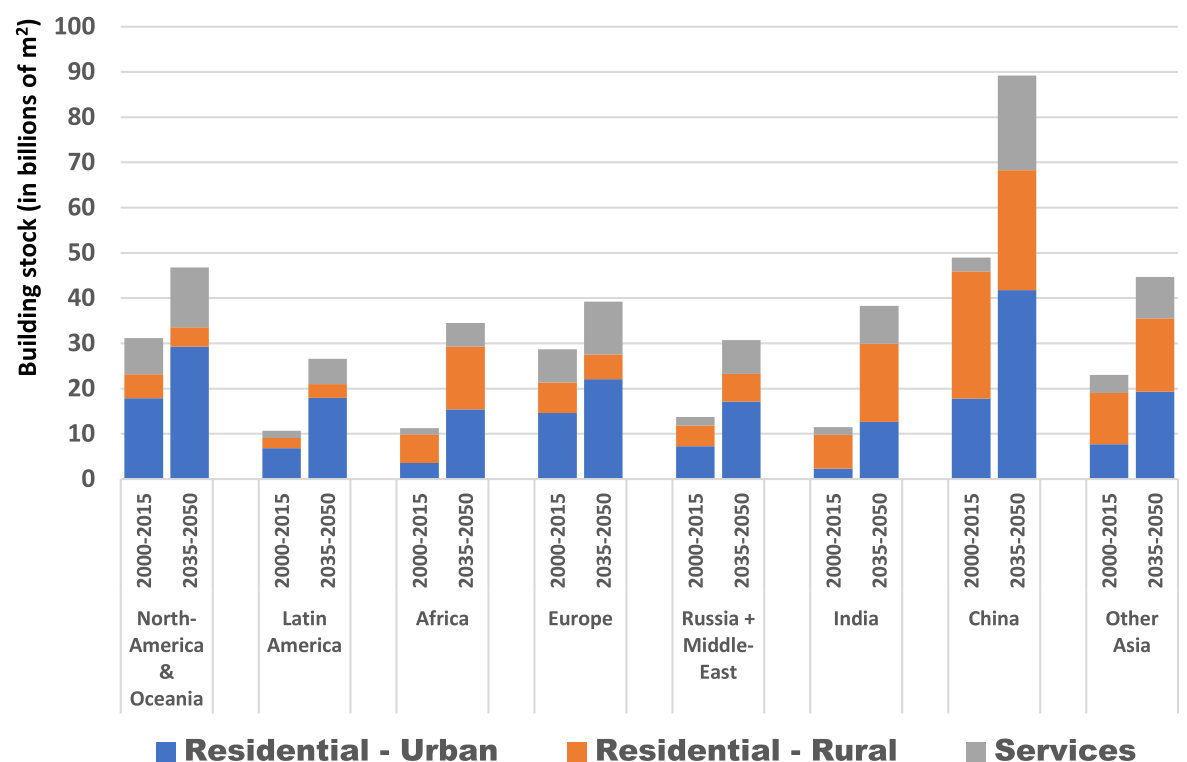

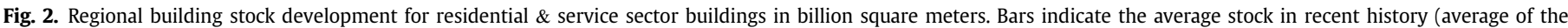
2000-2015 period) and by the end of the scenario period (average of the 2035-2050 period). For the per capita floor space demand, see Figure S9 in the SI.

contains regions with a steady growth in building stock like Europe, the US, Australia, but also the former Soviet- and Middle Eastern regions. In these regions, though the outflow of building floor space remains smaller than the inflow, the rate of building demolition slowly approaches the rate of the new construction leading to a slow stabilization. Secondly, in regions with a rapid economic development over the scenario period such as Latin America, Africa and Asian regions (Including India, but not China or Japan), the stock grows at an accelerated rate in the coming decades. This also means that the demand for construction of new buildings will remain much higher than the rate of demolition. Finally, two regions show a different result. Projections for China and Japan both show a stabilization and even a slight decrease in the total building stock towards the end of the scenario period. Towards 2050, this causes a decline in the demand for construction (inflow), while demolition activities (outflow) are increasing following a delayed response after a rapid historic expansion of the built environment. For China and Japan, the delay between inflow and outflow is smaller due to the application of lifetime distributions with a shorter mean lifetime (Table 3). As a result, these are the only two regions for which the outflow of building floor space approaches the volume of the inflow within the considered scenario period.
These observations have very relevant implications with regard to the secondary material availability as we will see in the following section.

\subsection{Material calculations (inflow-outflow)}

The development of building stock, inflow and outflow shown in Section 3.2 translates into projections for material demand. To calculate these we used the database specifying the building materials requirement per square meter, for four different residential buildings (Marinova et al., 2019), together with the material content of the four service-related building types as described in Section 2.1. In presenting the results of the material calculations we focus on the ratio between the inflow and the outflow, which gives an indication of the recycling potential, or more specifically, the potential for closing material loops in pursuit of achieving a circular economy. While maintaining the regional typologies as identified in Section 3.2, Fig. 5 shows the average ratio between material outflow and inflow based on the last 5 years of the scenario period (average of 2045-2050). Additionally, it specifies whether the material is used for or sourced from urban residential buildings, rural residential buildings or service-related buildings. 


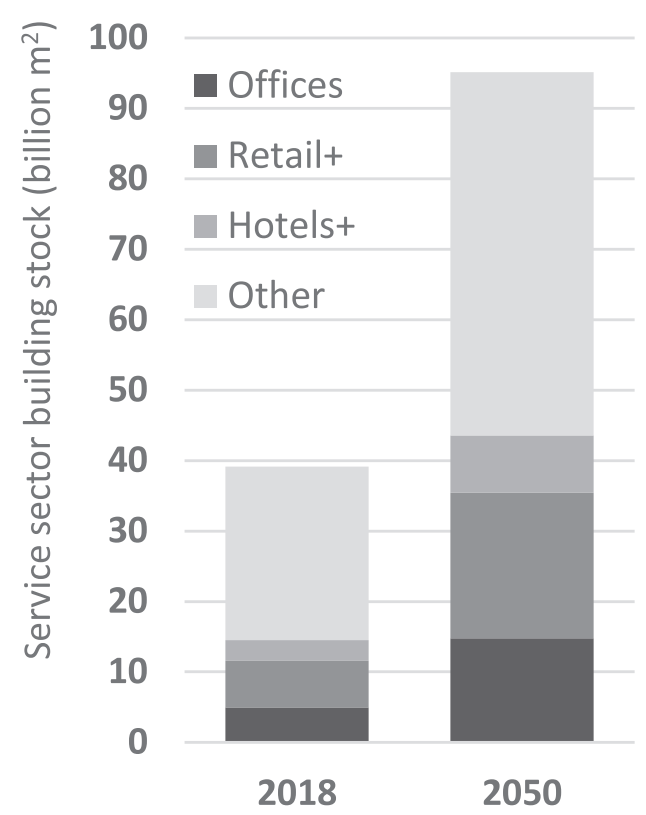

Fig. 3. Global stock of service sector buildings by building type in Billion square meters), current and by 2050 .

In general, Fig. 5 shows how the strong differences in regional typologies for floor space demand (Fig. 4) translate to distinct patterns in the material inflow and outflow as well. Towards 2050, the demand for new construction materials (in) will still strongly outweigh the amount of materials potentially available for recycling (out) in fast developing regions. In steady developed regions, however, the potential for closing the building material cycle will be larger, but it will not be possible yet to fully 'close the loop' even given a $100 \%$ end-of-life recycling rate. For Japan and China, the availability of some secondary building materials like concrete, glass and aluminium, should in theory be sufficient to fulfill the demand for construction purposes towards the end of the modelling period. The high material outflow in these regions, however, seem to be strongly related to the outflow of construction materials in rural areas. So the ongoing urbanization trends that explain these model outcomes may be an argument to expand the focus from urban mining to also include rural mining for the coming decades.

When we focus only on the urban residential fraction of the material flows, none of the presented regions show a potential for matching the demand of construction materials (inflow) entirely by using secondary supply (outflow), for any of the materials covered. Even though the model does not allocate service sector buildings to urban or rural areas specifically, we can safely assume that most of the service-related buildings would be built in urban areas. This would mean that service sector buildings aggravate the mismatch between secondary supply and demand for construction materials in urban areas.

Furthermore, our results show that by the end of the scenario period (2045-2050) the global annual demand for building materials increases to $769 \mathrm{Mt}$ steel, $11.9 \mathrm{Gt}$ concrete, $89 \mathrm{Mt}$ glass, $52 \mathrm{Mt}$ aluminium, $407 \mathrm{Mt}$ wood and $18 \mathrm{Mt}$ Copper. Compared to more recent years (2010-2015, not shown), this is an increase of $31 \%$ for steel, of $14 \%$ for concrete, of $24 \%$ for glass, of $24 \%$ for wood, of $5 \%$ for aluminium and of $58 \%$ for copper. The outflow of steel from demolished buildings in the 2045-2050 period (Fig. 5), however, would only be equivalent to $55 \%$ of the annual steel demand in this
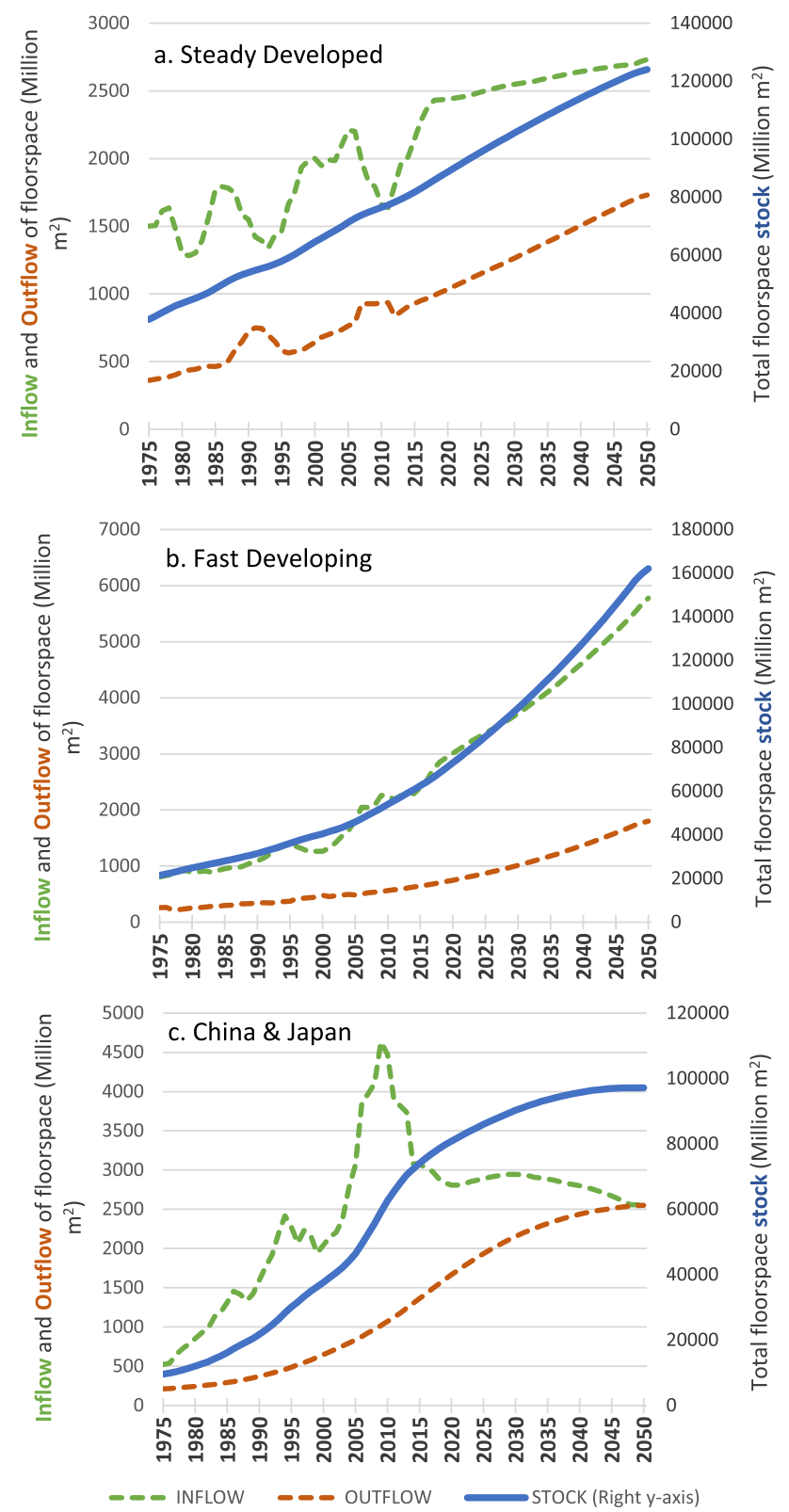

Fig. 4. Modelled development of (residential and service-related) building stock, inflow and outflow in Millions of square meters, for three regional typologies. Steady Developed regions (a) are: North-America, Europe, Australia, Former Soviet regions and the Middle East. Fast Developing regions (b) are: all Latin-American, African and Asian regions (except Japan \& China (c)). The data represents a 5-year moving average of the model outcomes.

period. Similarly, by the end of the modeling period, the outflow would only represent $64 \%$ of the sectoral demand for concrete, $71 \%$ of the sectoral aluminium demand, $55 \%$ of the sectoral wood demand, $64 \%$ of the glass demand and $55 \%$ of the copper demand. This discrepancy between outflow and inflow indicates that closing the loop for construction materials based on the urban mine alone seems highly unrealistic before the year 2050 . Especially given the fact that only a fraction of the secondary materials could actually be re-used (Nautiyal et al., 2015; Duan et al., 2015; Martínez-Rocamora et al., 2016).

Another noteworthy outcome shown in Fig. 5 is that buildings in the service sector play a more important role in the inflow and 



\author{
Services \\ Rural \\ Urban
}
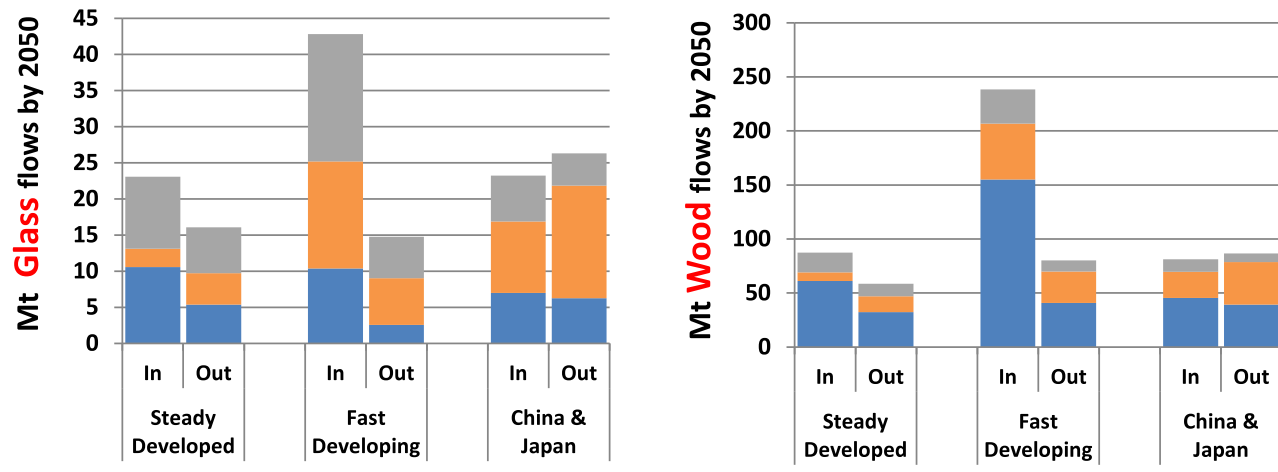

- Services

Rural

Urban
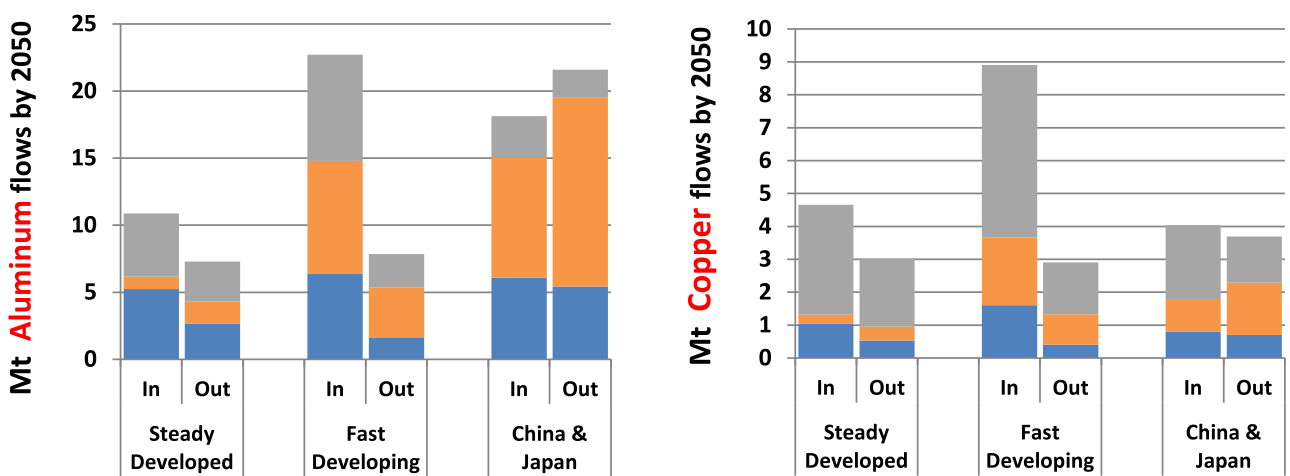

\title{
Services \\ Rural \\ urban
}

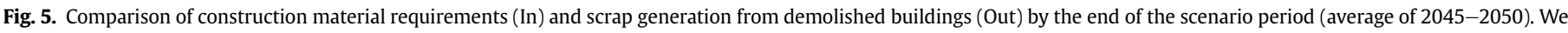


service sector buildings are shown in grey.

outflow of building materials, despite having a relatively small contribution to the stock (Fig. 2). The reasons for this are threefold. First of all, according to the studies used in our database, the material content per square meter in service-related buildings is simply a bit larger than in residential buildings for some materials, such as for copper, steel and glass for example. Secondly, the average lifetime of service sector buildings is smaller, leading to a higher contribution to both inflow and outflow of materials. Finally, in our model the global building stock of services expands faster than the global residential stock, which also results in a large contribution to the inflow.

The results presented in this section are only a selection of the available model output. For further details on regional model outcomes, please see the Supplementary Information and the Supplementary Data. Furthermore, the presented outcomes are a result of various choices and assumptions both for the data and the modelling. The following section provides a comparison of our model outcomes to existing studies, followed by some reflection on the assumptions by means of a sensitivity analysis and a reflection on the opportunities for model improvement, to end with the conclusions.

\section{Discussion and conclusions}

\subsection{Discussion}

\subsubsection{Comparison with existing literature}

To get a feeling for the value and probability of our model outcomes we start this discussion by a comparison to existing studies. We can only make these comparisons sporadically, and only to get a rough comparison, since the methodologies and categorization of material use do not always correspond between studies. We start with a comparison of the development of building stock in terms of floor space $\left(\mathrm{m}^{2}\right)$, where we are able to compare with a study by Amecke et al. (2013), who model the floor space demand in China to be about 62 Billion $\mathrm{m}^{2}$ (residential and services) by 2030, while our model suggests a total stock that is almost 35\% higher. Simultaneously, Amecke et al. model the total building stock in the United States to amount to 35 Billion $\mathrm{m}^{2}$ by 2030 , while our model produces a figure that is $16 \%$ lower. On the one hand this indicates that 
Table 4

Comparing model outcomes for the material stock per capita with available existing studies.

\begin{tabular}{|c|c|c|c|c|c|}
\hline Material & Year & Region & Model outcome (ton/cap) & Other studies (ton/cap) & References studies \\
\hline Cement & 2010 & Global & 11.1 & 10 & Cao et al. (2017) \\
\hline Cement & 2010 & EU & 15.4 & 23 & \\
\hline Steel & 2005 & EU & 3.42 & 1.3 to 3.5 & (Hatayama et al., 2010) and (Müller et al., 2010) \\
\hline Steel & 2005 & US & 2.66 & 2 to 4 & \\
\hline Aluminium & 2030 & Global & 0.27 & 0.20 & Estimates derived from (Liu et al., 2012) \\
\hline Aluminium & 2010 & Japan & 0.20 & 0.11 & \\
\hline
\end{tabular}

our model could benefit from improving the regional representation and one should be careful when using the detailed regional outcomes without reflection. On the other hand, it also indicates that the few given points of comparison do not indicate a consistent over- or underestimation of the stock.

Comparison with the in-stock material estimates for buildings with existing studies is done at the level of the stock per capita for different regions and materials in Table 4. It shows that for steel and cement outcomes are comparable and in the range of existing studies. For Aluminium our model seems to produce slightly higher estimates for in-use construction-related stock. This is a direct result of the studies used to define the material content database (Marinova et al., 2019).

Though the comparison in Table 4 indicates that the model presented in this paper is able to generate plausible outcomes for some materials and for some comparable regions, it does not mean that the detailed outcomes for every region and material will make sense. This is inevitable when compiling a model with a global scope like this. As indicated by Marinova et al. (2019) this is partly due to the sensitivity of our model to assumptions based on single study or data point, which is undesirable, but currently unsurmountable, given the data availability. We emphasize that the work presented here is an initial attempt at formulating a global model, and therefore provides plenty of sensitivities and opportunities for future improvements as discussed in the following sections.

\subsubsection{Sensitivity analysis}

To better understand the importance of some of the model assumptions to the outcomes we performed a sensitivity analysis. We defined four sensitivity variants, two of which were focused on changing the regression of service sector floorspace demand, one representing an alternative assumption on building lifetimes and one using an alternative set of material intensities based on the global mean values. The regression analysis on service sector floorspace demand was changed by allowing a higher value for alpha (representing the maximum per capita floorspace). In a second sensitivity variant the regression model based on a Gompertz function was replaced by an exponential decay function. Both alternative approaches to the regression did not lead to exceptional changes in the outcomes given that annual material demand for service sector buildings ended up only slightly lower (by $2 \%$ ) or higher (by about $8 \%$ ).

The implementation of normal lifetime distributions for both residential and service-related buildings, however, did have a larger effect on the outcomes by the end of the scenario period, leading to a decrease of annual material demand of $13 \%$ for service sector buildings, while decreasing material demand in residential buildings by up to $10 \%$. These deviation are unsurprising, given that lifetime assumptions are known to greatly affect inflows and outflows in building stock models (Miatto et al., 2017).

Finally, the implementation of a different set of material intensities based on the global mean value did have a large effect on some materials. Annual glass and wood demand in service sector buildings decreased by $23 \%$ and $35 \%$ respectively, due to relatively high material intensity estimates for the category of 'other' servicerelated buildings in the default analysis. While relatively high regional material intensities in China caused a decrease in the annual demand for aluminium (by $18 \%$ ) and concrete (by $20 \%$ ) towards 2050, in the sensitivity variant. Thus emphasizing the importance of validating the assumptions before using the regional model outcomes. For a detailed description of the assumptions and outcomes of the sensitivity analysis, please see the SI.

\subsubsection{Model improvements}

Future model improvements could be focused on including other non-residential buildings such as agricultural and industrial buildings and on a better understanding of regional dynamics. For example, implementing a regionally specific regression for the service-related floor space demand could improve regional results. Other potential improvements to the regression analysis could be made by performing a more elaborate multivariate analysis or multiple regression, to get a better understanding for other factors determining the service sector floor space demand. In general, the choice of a suitable regression model depends on the detail in the available data, but also on the scenario background. So the current model may not be suitable for use in scenarios other than the SSP2 (for additional reflection on the model specification, please see Section 2.2 in the SI)

A better representation of stock dynamics may also be achieved by allowing a dynamic lifetime (assuming different lifetimes for buildings built in different years) as for example applied by Hu et al. (2010), an approach that could for example be used to represent the stock of monumental buildings more accurately. Another improvement could be aimed at more realistic lifetime estimates, by critical reconciliation of literature based lifetime estimates with building statistics (See SI for an example). Furthermore, we would like to implement the option to account for material demand from maintenance and retrofitting, which is currently not possible. This could for example be done on the basis of lifetimes of partial building elements such as provided by Condeixa et al. (2017b). Another important improvement to make this study more relevant for practical policy making would be to translate the theoretical potential availability of scrapped building materials to a more realistic estimate for the actual recycling potential, given the practical collection and recycling practices. Finally, a suggestion for further work would be to implement this model in a global integrated assessment model such as IMAGE. This should contribute to a better understanding of interlinkages between material and energy demand, and would allow to assess the climate benefits of changing building technologies.

\section{Conclusions}

Based on the results of the current model, we are able to address the main objectives of this study.

Our model shows that service sector floor space currently amounts to about $17 \%$ of the global building stock. We also show that the service sector building stock becomes more important 
when considering the inflow and outflow of building materials due to faster stock growth, shorter average lifetimes and higher material content for some materials like copper, glass and steel. This category of buildings is often overlooked or modelled as part of a single 'buildings' category. However, given the large contribution to the inflow and outflow of some building materials, this study emphasizes the importance of explicit modelling of non-residential buildings when developing scenarios for the future built environment.

Our model projects a global residential building stock (expressed in square meters) that grows by about 50\% towards 2050 and it projects the global service-related building stock to grow by $150 \%$. Based on the resulting ratio between inflow and outflow of building floor space we were able to identify three distinct regional typologies. Regions like China and Japan are projected to have a slight population decrease towards 2050, which translates to a stabilizing building stock. Additionally, the short lifetimes of residential buildings in these regions cause a quick increase in the outflow of building stock, which closely matches the required inflow well before 2050 . This means that, for some materials, the maximum theoretical amount of scrapped building materials that would potentially be available for re-use or recycling matches the demand for new construction materials. Thus identifying opportunities for closing the loop for building materials according to the views of the circular economy. However, this cannot be achieved based on the urban mine alone. The ratio between inflow and outflow of urban building materials in China and Japan suggests that the demolition of rural housing might provide an even more important source for materials than the urban mine. Thus, suggesting that expanding the focus from urban mining to include rural mining might be worthwhile.

For all other regions (both steady developed and fast developing) the promise of a fully circular metabolism for construction materials seems highly unlikely before 2050 . In steady developed countries the slow population growth, combined with a continued GDP growth, ensures a steady growth in the building stock towards 2050. Given the longer lifetimes of houses in these regions, this means that the outflow catches up only slowly with the stabilizing inflow, which means that the availability of scrapped building materials will not be enough to fully supply the demand for new construction materials before 2050. A conclusion that is only amplified for fast developing regions like India, Latin-America and Africa. There, the annual demand for construction materials will continue to grow rapidly, with the outflow lagging behind substantially. Globally, this means that the outflow of construction materials is insufficient to provide the sectoral demand for new materials by the end of the modelling period. By 2050, scrapped copper from buildings could provide only $55 \%$ of the copper demand in construction, while for aluminium up to $71 \%$ of demand could be based on building scrap. As buildings are often the main contributor to the societal stocks of steel (Wang et al., 2015b) and concrete (Cao et al., 2017), they are an important driver of bulk material demand. This study thus identifies impressive challenges for achieving a global circular economy in the coming decades.

\section{Acknowledgements}

This work relies strongly on previous effort of the IMAGE team and of Vassilis Daioglou in particular. We would like to express our thankfulness for their feedback and help in shaping this manuscript. Furthermore, we would like to thank Stefan Pauliuk and cocontributors to the python Dynamic Stock Model, which has been essential in our analysis and is provided openly on Github (Pauliuk and Heeren, 2018). This dedication to open-source and transparent research inspired us to disclose our data and model where possible.
Finally, we also thank the reviewers for their valuable feedback and contributions to this work.

\section{Appendix A. Supplementary data}

Supplementary data to this article can be found online at https://doi.org/10.1016/j.jclepro.2019.118658.

\section{References}

Amecke, H., et al., 2013. Buildings Energy Efficiency in China, Germany, and the United States. San Fr. USA Clim. Policy Initiat.

Augiseau, V., Barles, S., 2017. Studying construction materials flows and stock: a review. Resour. Conserv. Recycl. 123, 153-164.

Bevington, P.R., Robinson, D.K., 2003. Data Reduction and Error Analysis for the Physical Sciences. McGraw-Hill. https://doi.org/10.1063/1.4823194.

Bressand, F., Zhou, N., Lin, J. al, 2007. Energy use in commercial building in China: current situation and future scenarios. In: ECEEE Summer Study Proceedings (2007).

Buyle, M., Braet, J., Audenaert, A., 2013. Life cycle assessment in the construction sector: a review. Renew. Sustain. Energy Rev. 26, 379-388.

Buyle, M., Braet, J., Audenaert, A., 2013. Life cycle assessment in the construction sector: a review. Renew. Sustain. Energy Rev. 26, 379-388.

Cao, Z., Shen, L., Løvik, A.N., Müller, D.B., Liu, G., 2017. Elaborating the history of our cementing societies: an in-use stock perspective. Environ. Sci. Technol. 51 $11468-11475$.

Cao, Z., et al., 2018. A probabilistic dynamic material flow analysis model for Chinese urban housing stock. J. Ind. Ecol. 22, 377-391.

Coffey, B., et al., 2009. Towards a very low-energy building stock: modelling the US commercial building sector to support policy and innovation planning. Build. Res. Inf. 37, 610-624.

Condeixa, K., Haddad, A., Boer, D., 2017. Material flow analysis of the residential building stock at the city of Rio de Janeiro. J. Clean. Prod. 149, 1249-1267.

Condeixa, K., Haddad, A., Boer, D., 2017. Material flow analysis of the residential building stock at the city of Rio de Janeiro. J. Clean. Prod. 149, 1249-1267.

Daigo, I., Igarashi, Y., Matsuno, Y., Adachi, Y., 2007. Accounting for steel stock in Japan. ISIJ Int. 47, 1065-1069.

Daigo, I., Iwata, K., Oguchi, M., Goto, Y., 2017. Lifetime distribution of buildings decided by economic situation at demolition: D-based lifetime distribution. Procedia CIRP 61, 146-151.

Daioglou, V., van Ruijven, B.J., van Vuuren, D.P., 2012. Model projections for household energy use in developing countries. Energy 37, 601-615.

Davis, J., et al., 2007. Time-dependent material flow analysis of iron and steel in the UK: Part 2. Scrap generation and recycling. Resour. Conserv. Recycl. 51, 118-140.

Deng, Y.Y., Blok, K., van der Leun, K., 2012. Transition to a fully sustainable global energy system. Energy Strategic Rev. 1, 109-121.

Dericks, G., Potts, R., Caldecott, B., 2018. Stranded Property A Ssets in China's Resource-Based Cities: Implications for Financial Stability?.

Duan, H., Wang, J., Huang, Q., 2015. Encouraging the environmentally sound management of C\&D waste in China: an integrative review and research agenda. Renew. Sustain. Energy Rev. 43, 611-620.

Fishman, T., Schandl, H., Tanikawa, H., 2016. Stochastic analysis and forecasts of the patterns of speed, acceleration, and levels of material stock accumulation in society. Environ. Sci. Technol. 50, 3729-3737.

Ghisellini, P., Cialani, C., Ulgiati, S., 2016. A review on circular economy: the expected transition to a balanced interplay of environmental and economic systems. J. Clean. Prod. 114, 11-32.

Gruhler, K., Deilmannl, C., 2017. Materialaufwand von Nichtwohngebäuden - teil II. In: Fraunhofer IRB Verlag.

Gutowski, T.G., Sahni, S., Allwood, J.M., Ashby, M.F., Worrell, E., 2013. The energy required to produce materials: constraints on energy-intensity improvements, parameters of demand. Philos. Trans. R. Soc. A Math. Phys. Eng. Sci. 371 20120003.

Hatayama, H., Daigo, I., Matsuno, Y., Adachi, Y., 2009. Assessment of the recycling potential of aluminum in Japan, the United States, Europe and China. Mater. Trans. 50, 650-656.

Hatayama, H., Daigo, I., Matsuno, Y., Adachi, Y., 2010. Outlook of the world steel cycle based on the stock and flow dynamics. Environ. Sci. Technol. 44, 6457-6463.

Heeren, N., Fishman, T., 2019. A database seed for a community-driven material intensity research platform. Sci. Data 6, 23.

Heeren, N., et al., 2015. Environmental impact of buildings-what matters? Environ. Sci. Technol. 49, 9832-9841.

Hu, M., et al., 2010. Iron and steel in Chinese residential buildings: a dynamic analysis. Resour. Conserv. Recycl. 54, 591-600.

Huang, T., Shi, F., Tanikawa, H., Fei, J., Han, J., 2013. Materials demand and environmental impact of buildings construction and demolition in China based on dynamic material flow analysis. Resour. Conserv. Recycl. 72, 91-101.

IEA. Commercial, 2012. Buildings energy consumption survey (CBECS). Available at. https://www.eia.gov/consumption/commercial/.

IEA. Residential, 2015. Energy consumption survey (RECS). Available at. https:// www.eia.gov/consumption/residential/. 
Kapur, A., Keoleian, G., Kendall, A., Kesler, S.E., 2008. Dynamic modeling of in-use cement stocks in the United States. J. Ind. Ecol. 12, 539-556.

Kapur, A., Keoleian, G., Kendall, A., Kesler, S.E., 2008. Dynamic modeling of in-use cement stocks in the United States. J. Ind. Ecol. 12, 539-556.

Kashkooli, A.M.S., Vargas, G.A., Altan, H., 2014. A semi-quantitative framework of building lifecycle analysis: demonstrated through a case study of a typical office building block in Mexico in warm and humid climate. Sustain. Cities Soc. 12, 16-24.

Kavgic, M., et al., 2010. A review of bottom-up building stock models for energy consumption in the residential sector. Build. Environ. 45, 1683-1697.

Kellenberger, D., et al., 2007. Life Cycle Inventories of Building Products. https:// doi.org/10.1109/SECON.2017.7925283 ecoinvent report No. 7.

Kofoworola, O.F., Gheewala, S.H., 2009. Life cycle energy assessment of a typical office building in Thailand. Energy Build. 41, 1076-1083.

Krausmann, F., et al., 2017. Global socioeconomic material stocks rise 23-fold over the 20th century and require half of annual resource use. Proc. Natl. Acad. Sci. $114,1880-1885$.

Krook, J., Baas, L., 2013. Getting serious about mining the technosphere: a review of recent landfill mining and urban mining research. J. Clean. Prod. 55, 1-9.

Kumanayake, R., Luo, H., Paulusz, N., 2018. Assessment of material related embodied carbon of an office building in Sri Lanka. Energy Build. 166, 250-257.

Liu, G., Bangs, C.E., Müller, D.B., 2012. Stock dynamics and emission pathways of the global aluminium cycle. Nat. Clim. Chang. 3, 338.

Machinchick, T., Freas, B., 2018. Global Building Stock Database, Commercial and Residential Building Floor Space by Country and Building Type: 2017-2026.

Marcellus-Zamora, K.A., Gallagher, P.M., Spatari, S., Tanikawa, H., 2016. Estimating materials stocked by land-use type in historic urban buildings using spatiotemporal analytical tools. J. Ind. Ecol. 20, 1025-1037.

Marinova, S., Deetman, S., Van der Voet, E., 2019. Construction materials database and stock analysis of the global residential built environment: 1970-2050. J. Clean. Prod submitted for publication.

Martínez-Rocamora, A., Solís-Guzmán, J., Marrero, M., 2016. LCA databases focused on construction materials: a review. Renew. Sustain. Energy Rev. 58, 565-573.

McMillan, C.A., Moore, M.R. Keoleian, G.A., Bulkley, JW., 2010. Quantifying U.S. aluminum in-use stocks and their relationship with economic output. Ecol. Econ. 69, 2606-2613.

Miatto, A., Schandl, H., Tanikawa, H., 2017. How important are realistic building lifespan assumptions for material stock and demolition waste accounts? Resour. Conserv. Recycl. 122, 143-154.

Müller, D.B., 2006. Stock dynamics for forecasting material flows-case study for housing in The Netherlands. Ecol. Econ. 59, 142-156.

Müller, D.B., et al., 2013. Carbon emissions of infrastructure development. Environ. Sci. Technol. 47, 11739-11746.

Murakami, S., Oguchi, M., Tasaki, T., Daigo, I., Hashimoto, S., 2010. Lifespan of commodities, Part I. J. Ind. Ecol. 14, 598-612.

Murakami, S., Oguchi, M., Tasaki, T., Daigo, I., Hashimoto, S., 2010. Lifespan of commodities, Part I. J. Ind. Ecol. 14, 598-612.

Müller, D.B., Wang, T., Duval, B., 2010. Patterns of iron use in societal evolution $\S$ Environ. Sci. Technol. 45, 182-188.

Nautiyal, H., Shree, V., Khurana, S., Kumar, N., Varun, 2015. Recycling potential of building materials: a review. In: Muthu, S.S. (Ed.), Environmental Implication of Recycling and Recycled Products. Springer Singapore, pp. 31-50. https:// doi.org/10.1007/978-981-287-643-0_2.

Nomura, K., Suga, Y., 2013. Asset Service Lives and Depreciation Rates Bas Ed on Disposal Data in Japan.

Novikova, A., Csoknyai, T., Szalay, Z., 2018. Low carbon scenarios for higher therma comfort in the residential building sector of South Eastern Europe. Energy Effic $11,845-875$.

OECD, Eurostat, 2015. Eurostat-OECD Survey of National Practices in Estimating Net Stocks of Structures. OECD.

Oka, T., Suzuki, M., Konnya, T., 1993. The estimation of energy consumption and amount of pollutants due to the construction of buildings. Energy Build. 19, 303-311.

Olaya, Y., Vásquez, F., Müller, D.B., 2017. Dwelling stock dynamics for addressing housing deficit. Resour. Conserv. Recycl. 123, 187-199.

Olson, B.D., 2011. Residential Building Material Reuse in Sustainable Construction. Washington State University.

Pauliuk, S., Heeren, N., 2018. Open Dynamic Material Systems Model.

Pauliuk, S., Hertwich, E.G., 2015. Socioeconomic metabolism as paradigm for studying the biophysical basis of human societies. Ecol. Econ. 119, 83-93.

Pauliuk, S., Müller, D.B., 2014. The role of in-use stocks in the social metabolism and in climate change mitigation. Glob. Environ. Chang. 24, 132-142.

Pauliuk, S., Wang, T., Müller, D.B., 2013. Steel all over the world: estimating in-use stocks of iron for 200 countries. Resour. Conserv. Recycl. 71, 22-30.

Reyna, J.L., Chester, M.V., 2015. The growth of urban building stock: unintended lock-in and embedded environmental effects. J. Ind. Ecol. 19, 524-537.

Rosselló-Batle, B., Moià, A., Cladera, A., Martínez, V., 2010. Energy use, CO2 emissions and waste throughout the life cycle of a sample of hotels in the Balearic Islands. Energy Build. 42, 547-558.

Sandberg, N.H., Sartori, I., Brattebø, H., 2014. Sensitivity analysis in long-term dynamic building stock modeling-exploring the importance of uncertainty of input parameters in Norwegian segmented dwelling stock model. Energy Build. 85, 136-144.

Sartori, I., Wachenfeldt, B.J., Hestnes, A.G., 2009. Energy demand in the Norwegian building stock: scenarios on potential reduction. Energy Policy 37, 1614-1627.

Schebek, L., et al., 2017. Material stocks of the non-residential building sector: the case of the Rhine-Main area. Resour. Conserv. Recycl. 123, 24-36.

Stehfest, E., Vuuren, D. van, Kram, T., Bouwma, L., 2014. Integrated Assessment of Global Environmental Change with IMAGE 3.0. PBL Netherlands Environmental Assessment Agency.

Stephan, A., Athanassiadis, A., 2017. Quantifying and mapping embodied environmental requirements of urban building stocks. Build. Environ. 114, 187-202.

Tanikawa, H., Fishman, T., Okuoka, K., Sugimoto, K., 2015. The weight of society over time and space: a comprehensive account of the construction material stock of Japan. J. Ind. Ecol. 19, 778-791, 1945-2010.

Teh, S.H., Wiedmann, T., Schinabeck, J., Moore, S., 2017. Replacement scenarios for construction materials based on economy-wide hybrid LCA. Procedia Eng. 180, 179-189.

UNData, 2018. Per Capita GDP at Current Prices. National Accounts Estimates of Main Aggregates. United Nations Statistics Division. Available at. http://data.un. org/Data.aspx? q=GDP\&d=SNAAMA\&f=grID\%3A101\%3BcurrID\%3AUSD\% 3BpcFlag\%3A1\#SNAAMA.

UNData, 2018. GVA by Kind of Economic Activity. National Accounts; United Nations Statistics Division. Available at. http://data.un.org/. (Accessed 19 November 2018).

van Ruijven, B.J., et al., 2016. Long-term model-based projections of energy use and $\mathrm{CO} 2$ emissions from the global steel and cement industries. Resour. Conserv. Recycl. 112, 15-36.

van Vuuren, D.P., et al., 2017. The Shared Socio-economic Pathways: trajectories for human development and global environmental change. Glob. Environ. Chang. $42,148-152$.

van Vuuren, D.P., et al., 2017. Energy, land-use and greenhouse gas emissions trajectories under a green growth paradigm. Glob. Environ. Chang. 42, 237-250.

Vásquez, F., Løvik, A.N., Sandberg, N.H., Müller, D.B., 2016. Dynamic type-cohorttime approach for the analysis of energy reductions strategies in the building stock. Energy Build. 111, 37-55.

Wang, T., Tian, X., Hashimoto, S., Tanikawa, H., 2015. Concrete transformation of buildings in China and implications for the steel cycle. Resour. Conserv. Recycl. 103, 205-215.

Wang, T., Müller, D.B., Hashimoto, S., 2015. The ferrous find: counting iron and steel stocks in China's economy. J. Ind. Ecol. 19, 877-889.

Wiedenhofer, D., Steinberger, J.K., Eisenmenger, N., Haas, W., 2015. Maintenance and expansion: modeling material stocks and flows for residential buildings and transportation networks in the EU25. J. Ind. Ecol. 19, 538-551.

Zhang, X., Geltner, D., de Neufville, R., 2018. System dynamics modeling of Chinese urban housing markets for pedagogical and policy analysis purposes. J. Real Estate Finance Econ. 57, 476-501. 